\title{
Abdominal versus vaginal hysterectomy: Appraisal of indications and complications in a Nigerian Federal Medical Centre
}

\author{
Umeora OUJ, 1 Onoh RC, ${ }^{2}$ Eze JN ', Igberase $\mathrm{GO}^{3}$ \\ 'Department of Obstetrics \& Gynaecology, Ebonyi State University, Abakaliki. Ebonyi State Nigeria. \\ ${ }^{2}$ Department of Obstetrics \& Gynaecology, Federal Medical Centre, Abakaliki, Ebonyi State Nigeria. \\ ${ }^{3}$ Department of Obstetrics \& Gynaecology, Delta State University Abraka - Nigeria.
}

\begin{abstract}
Aims: To compare hysterectomies performed via the abdominal and vaginal routes in terms of indications and associated complications.

Methods: Review of retrospective data on all cases of hysterectomies performed at the Federal Medical Centre Abakaliki over a six-year period (January 2000 to December 2005).

Results: There were a total of 62 hysterectomies. Of these, 33 (52.2\%) were abdominal hysterectomies while 29 (46. 8\%) were vaginal hysterectomies. Hysterectomy was carried out predominantly for grand multiparous women $[21(72.4 \%)$ and 21 (63.7\%) were abdominal and vaginal hysterectomies respectively]. The mean ages of the patients were 48.8 years and 55.5 years for the abdominal and vaginal operations respectively. The only indication for vaginal hysterectomy in this study was uterovaginal prolapse while uterine fibroid was the commonest indication for abdominal hysterectomy. Complications and duration of hospital stay were more following abdominal hysterectomy.

Conclusion: There is need for training and retraining of specialist gynaecologists and trainee residents on procedures of hysterectomies, especially vaginal hysterectomy to expand the indications for the vaginal surgery which is attended with less postoperative morbidity.
\end{abstract}

Key words: indications, complications, route, pyrexia, wound, Abakaliki.

\section{Introduction}

Hysterectomy is the most common gynaecological surgical procedure carried out on women globally, with over 100,000 procedures performed annually in England and 600,000 in the United States. ${ }^{1}$ Hysterectomies are commonly performed in many tertiary health institutions in Nigeria. It accounts for $28 \%$ of all major gynecological operations at the University College Hospital, Ibadan, Nigeria: coming after salpingectomy for ectopic pregnancy. ${ }^{2}$ Therefore a regular audit of the surgery is necessary for improved healthcare delivery in any centre.
All large-scale surveys of hysterectomies show that $70-80 \%$ of hysterectomies are performed by the abdominal approach except in uterovaginal prolapse for which the vaginal route is normally used and accounts for $10 \%$ of all hysterectomies performed. ${ }^{3,4}$ When both approaches are compared, vaginal hysterectomy is associated with fewer complications, lower need for blood transfusion and shorter period of postoperative recovery, than total abdominal hysterectomy. The route of hysterectomy is based on clinical and technical factors such as the primary indication for the operation, uterine weight, previous pelvic surgery, previous vaginal deliveries or the need for morcellation or concomitant adnexectomy.

Correspondence

Dr.OUJ Umeora

PO Box 980, Abakaliki. Ebonyi State. Nigeria Postal code: 480001

Email:oujair@yahoo.com 
From the inception of this tertiary health institution, no audit of gynaecological surgical procedures has ever been carried out. This study therefore evaluates vaginal and abdominal hysterectomies in terms of their rates, indications, complications, as well as the sociobiological variables of the patients. It will hence provide baseline data for hysterectomies in the centre.

\section{Methods}

\section{Study background}

The Federal Medical Centre Abakaliki is a tertiary health institution receiving referrals from the entire State and her neighbours. It started off in the 1960s as a General Hospital and was up graded to a Federal Medical Centre in 1997. The major transformation occurred in 2003 when it was accredited for residency training in the major clinical departments of Internal Medicine, Surgery, Child Health and Obstetrics/Gynaeclogy. Just prior to this was an influx of consultants as well as other middle class medical staff to compliment the new status.

The Obstetrics and Gynaecology Department has seven consultants and 16 residents at various levels of training. It has a 24-bedded ward and an operating theatre.

\section{Study design}

A retrospective analysis of all cases of abdominal and vaginal hysterectomies at Federal Medical Centre, from January 2000 to December 2005 was undertaken. The case files, theatre records and ward records of the patients were retrieved from the records department of the hospital. Information obtained from the case records included parity, age, social class, indication for surgery, duration of hospitalization post surgery and complication following surgery.

Data was analyzed using the epi info statistical software version 3.3.2 (2005) and presented in simple tables. The chi square test was employed to test for significance with a $\mathrm{p}$ value of less than 0.05 taken as significant.

\section{Results}

There were 69 hysterectomies, accounting for $17 \%$ of the 406 elective major gynaecological operations over the years of study. Sixty-two files $(89.9 \%)$ were retrieved and therefore analyzed. Of the 62 hysterectomies, $33(52.2 \%)$ were abdominal hysterectomy, while $29(47.8 \%)$ were performed via the vaginal route.
Table 1 showed the socio-biological variables of the patients. Majority of abdominal hysterectomies $12(36.4 \%)$ were done for women aged between 51 and 60 years whereas vaginal hysterectomy was mainly in those within the age bracket of $61-70$ years $(31.0 \%)$. The second most common age group for abdominal hysterectomy was 41-50 years while that of vaginal hysterectomy was 51-60 years. The mean ages were $48.8 \pm 6.1$ years $( \pm 2 S D)$ and $55.5 \pm 6.1$ years $( \pm 2 S D)$ for the abdominal and vaginal surgeries respectively. The differences in the age distribution of the patients were not statistically significant $\left(\mathrm{X}^{2}=0.01, \mathrm{p}\right.$ value 0.91$)$. Parity distribution showed that most of the women were grandmultipara, $63.7 \%$ and $72.4 \%$ for abdominal and vaginal hysterectomies respectively. No nulliparous woman had vaginal hysterectomy while three nulliparas underwent abdominal hysterectomy. The difference in parity distribution did not attain statistical significance $\left(x^{2}=0.00\right.$ and $p$ value 0.996$)$. In terms of occupation, farming was the predominant occupation engaged in by the women who underwent hysterectomy. However while it constituted $39.4 \%$ in the abdominal group, it accounted for $65.5 \%$ in the vaginal group. This difference was significant $\left(\mathrm{X}^{2}=\right.$ 4.15 and $p$ value 0.04$)$.

The indications for hysterectomies are shown in table 2. Symptomatic uterine fibroid was the most common indication for abdominal hysterectomy 18 (54.5\%). This was followed by cervical intraepithelial neoplasia $7(21.2 \%)$ and postmenopausal bleeding 5 $(15.2 \%)$. Uterovaginal prolapse was the only indication for vaginal hysterectomy. Third degree uterovaginal prolapse $20(69 \%)$ was the commonest degree of uterovaginal prolapse encountered.

Patients who had abdominal hysterectomy significantly developed complications more than those who had hysterectomies via the vaginal route $(84.8 \%$ versus $58.6 \%$ ). The Chi square was 5.52 while the $\mathrm{p}$ value was 0.02 . The pattern of the complications is shown in Table 3. Abdominal pain $12(36.4 \%)$ was the commonest complication following abdominal hysterectomy whereas pyrexia (17.2\%) was the commonest complication for vaginal hysterectomy.. The second most common complication for abdominal hysterectomy was pyrexia, which accounted for $6(18.2 \%)$ whereas it was vaginal bleeding $4(13.8 \%)$ in vaginal hysterectomy. The duration of postoperative hospitalization is shown in Table 4.

Over $82 \%$ of the patients who had vaginal hysterectomy were discharged within one week of the surgery while a corresponding percentage $(>84 \%)$ who had abdominal hysterectomy stayed for more than one week before 
Table 1. Age and parity distribution of patients who underwent hysterectomy.

\begin{tabular}{|c|c|c|c|c|c|}
\hline Characteristics & Abdominal $\mathrm{N}=33$ & Hysterectomy & $\%$ & Vaginal $n=29$ & Hysterectomy $\%$ \\
\hline \multicolumn{6}{|l|}{ Age (years) } \\
\hline $21-30$ & 1 & 3.0 & & - & - \\
\hline $31-40$ & 7 & 21.2 & & 3 & 10.3 \\
\hline $41-50$ & 9 & 27.3 & & 7 & 24.1 \\
\hline $51-60$ & 12 & 36.4 & & 8 & 27.6 \\
\hline $61-70$ & 4 & 12.1 & & 9 & 31.0 \\
\hline $71-80$ & - & - & & 2 & 6.9 \\
\hline \multicolumn{6}{|l|}{ Parity } \\
\hline 0 & 3 & 9.1 & & - & - \\
\hline $1-4$ & 9 & 27.3 & & 8 & 27.6 \\
\hline $5-9$ & 15 & 45.5 & & 11 & 37.9 \\
\hline$\geq 10$ & 6 & 18.2 & & 10 & 34.5 \\
\hline Trading Occupation & 4 & 12.1 & & 3 & 10.3 \\
\hline Farming & 13 & 39.4 & & 19 & 65.5 \\
\hline Civil Servant & 5 & 15.2 & & 3 & 10.3 \\
\hline Housewife & 11 & 33.3 & & 4 & 13.8 \\
\hline
\end{tabular}

Table 2. Indications for hysterectomy.

\begin{tabular}{|c|c|c|c|c|}
\hline Indications & Abdominal $\mathrm{N}=33$ & Hysterectomy \% & Vaginal $n=29$ & Hysterectomy $\%$ \\
\hline Postmenopausal bleeding & 5 & 15.2 & - & - \\
\hline $\mathrm{CIN}^{*}$ & 7 & 21.2 & - & - \\
\hline Chronic cervicitis & 2 & 6.1 & - & - \\
\hline Uterine Fibroids & 18 & 54.5 & - & - \\
\hline Uterine inversion & 1 & 3.0 & - & - \\
\hline Uterovaginal Prolapse & - & - & 29 & 100.0 \\
\hline
\end{tabular}

*CIN : Cervical Intraepithelial Neoplasia.

discharge from the hospital with $6.2 \%$ staying over three weeks. The differences in hospitalization post surgery were significant $\left(\mathrm{X}^{2}\right.$ for trend $=22.185$, $\mathrm{p}$ value $=0.000)$

\section{Discussion}

The number of gynaecological operations was used as denominator in calculating the hysterectomy rate in this study. This was preferred to the total gynaecological admissions since this is a surgical procedure and moreover gynaecological admissions would have excluded patients that had day case surgeries. The hysterectomy rate of 170 per 1000 in this study is lower than that in the developed countries with rates of 330 per 1000 women ${ }^{5}$ in United States of America and also the 280/1000 rate from Ibadan Southwest Nigeria $^{2}$, but higher than the rate of 57 per 1000 from the neighouring city of Enugu ${ }^{6}$ also in Southeast Nigeria. The ratio of abdominal to vaginal hysterectomies in this study was 1.1 to 1 . This does not tally with that seen in developed countries because of the aversion of our women to surgery. Hence hysterectomy is reluctantly accepted only when faced with obvious life threatening pathology of the uterus or its adnexae, such that whereas dysfunctional uterine bleeding (DUB), dysmenorrhoea and suspected adenomyosis top the indications for abdominal hysterectomy in developed countries ${ }^{7}$, they are rarely causes for removal of the uterus in developing countries. Moreover, most Igbo women of Southeast Nigeria not only derive reassurances of sexuality and femininity from their cyclical menstrual periods but also may subscribe to the traditional belief that presupposes that hysterectomised women present with primary infertility upon reincarnation.

In concordance with literature, vaginal hysterectomy was performed on older women and women whose occupations involved increases in intra abdominal pressure like the farmers. Uterovaginal prolapse was the only indication in this group of women. It is known 
Table 3. Complications following Hysterectomy during the review period.

\begin{tabular}{|c|c|c|c|c|c|}
\hline Complications & Abdominal $\mathrm{N}=33$ & Hysterectomy & $\%$ & Vaginal $n=29$ & Hysterectomy $\%$ \\
\hline Undue abdominal pain & 12 & 36.4 & & 2 & 6.9 \\
\hline Pyrexia & 6 & 18.2 & & 5 & 17.2 \\
\hline Wound infection & 5 & 15.2 & & 3 & 10.3 \\
\hline Undue vaginal bleeding & 1 & 3.0 & & 4 & 13.8 \\
\hline Post operative anaemia & 3 & 9.1 & & 1 & 3.5 \\
\hline Vault Prolapse & - & - & & 2 & 6.9 \\
\hline Death & 3 & 9.1 & & - & - \\
\hline
\end{tabular}

Table 4. Duration of hospitalization post hysterectomy

\begin{tabular}{|c|c|c|c|c|c|}
\hline Duration (days) & Abdominal $\mathrm{N}=33$ & Hysterectomy & $\%$ & Vaginal $n=29$ & Hysterectomy $\%$ \\
\hline$\leq 7$ & 5 & 15.2 & & 24 & 82.4 \\
\hline $8-14$ & 19 & 57.6 & & 4 & 13.8 \\
\hline $15-21$ & 7 & 21.2 & & 1 & 3.4 \\
\hline $22-28$ & 2 & 6.1 & & - & - \\
\hline
\end{tabular}

that degenerative changes of aging and menopause deplete estrogenic support of the endopelvic fascia, leading to genital prolapse. This aetiopathogenic factor was reinforced by the fact that grandmultiparity was easily identified as the risk factor underlying $72.4 \%$ of the vaginal hysterectomies. Grandmultiparity especially with difficult vaginal delivery could result in damage to pelvic support structures. ${ }^{8}$ In developed countries on the other hand, vaginal hysterectomy is the treatment of choice for menorrhagia, dysfunctional uterine bleeding, adenomyosis and fibroid when not contraindicated. . $^{4}$

Meanwhile, uterine fibroid (54.5\%) was the commonest indication for abdominal hysterectomy in this study in contradiction to the developed countries where DUB is the commonest indication. DUB and endometriosis are relatively uncommon in Negroid race and the finding here is similar to that of Eze and Otubu ${ }^{9}$ in 1981. Uterine fibroid has been reported to account for almost a third of all hysterectomies. ${ }^{7}$ Though all the fibroids in this study were treated with hysterectomy via the abdominal route, symptomatic fibroids with less than 12 week Uterine size or uterine volume of less than $400 \mathrm{~cm}^{3}$ can be dealt with via the vaginal route. ${ }^{10,11}$ Vaginal hysterectomy is preferred because of shorter hospitalization of 2- 4 days (average of 2.6 days) and a better economic cost. In this study, over $82 \%$ of the patients who had vaginal hysterectomy were hospitalized for less than a week with a modal stay of five days, whereas in those who underwent abdominal hysterectomy, $57.6 \%$ stayed between eight and fourteen days in the hospital and a modal stay of nine days.
Complications following abdominal hysterectomy are reported to be $70 \%$ higher than that for vaginal hysterectomy. ${ }^{4}$ In this review, undue abdominal pain (36.4\%) pyrexia (18.2\%) and wound infection (15.2\%) were the commonest complications attending abdominal hysterectomy. Following vaginal hysterectomy, pyrexia 5(17.2\%) was the common complication noted. The incidence of pyrexia complicating abdominal and vaginal hysterectomies in this study was almost $1: 1$, contrary to an earlier report of 2:1. ${ }^{12}$ Three deaths were recorded following abdominal hysterectomy and none from vaginal hysterectomy over the study period. This is in agreement with the finding of $0.00-0.01 \%$ in other studies showing that in all hysterectomies the vaginal route is the safest ${ }^{6,13}$. However, it could not be immediately ascertained the primary causes of death in those patients as autopsy was not performed in any of those. There is strong cultural aversion to post mortem examinations among the Igbo population of Southeastern Nigeria. In this study, the overall complication rate was highest with abdominal hysterectomy with a rate of $25(75.8 \%)$ as against $17(58.6 \%)$ for vaginal hysterectomy. Hence, operative morbidity, cosmetics and reouperation favor the vaginal approach.

The gold standard for decision-making is absence of contra-indications to vaginal hysterectomy and the findings on examination under anaesthesia. When in doubt of contra-indication, trial of vaginal hysterectomy will be of immense help. Abdominal hysterectomy must be reserved for cases in which the vaginal route is 
contraindicated and laparoscopic assisted vaginal hysterectomy is either risky or difficult. ${ }^{4}$

\section{Conclusion}

Vaginal hysterectomy was associated with less morbidity than abdominal hysterectomy but its indication still appears quite limited in this setting. There is need for further training of specialists and residents in operative techniques of vaginal hysterectomy to expand the indications and applicability in gynaecological surgery.

\section{References}

1. Vassey MP, Villard-Mackintosh L, McPherson K, Coulter A, Yeates D. The epidemiology of hysterectomy: findings in a large cohort study. Br J Obstet Gynecol 1992; 99: 402-407.

2. Arowojulu AO. Hysterectormy. In: Okonofua F ,Odunsi K (Eds). Contemporary Obstetrics And Gynaecology for developing countries. $1^{\text {st }}$ edition. Benin City: Women's Health And Action Research Center, 2003; pp: 227-242.

3. Maresh MJ, Metcalfe MA, McPherson K, Overton C, Hall V, Hargreaves S, Bridgman J et al. The value of national hysterectomy study: description of the patients and their surgery. $\mathrm{Br}$ J Obstet Gynecol 2002; 109: 302-312.

4. Sheth SS. The scope of vaginal hysterectomy. Eur J Obstet Gynaecol Rep Biol 2004; 115: 224231
5. Wilcox LS, Koonin LM, Pokras R, Strauss LT, Xia Z, Peterson HB. Hysterectomy in the United States 1988-1990. Obstet Gynecol, 1994; 83(4):549555.

6. Onah HE, Ugona MC. An audit of vaginal hysterectomies in Enugu, Nigeria. Trop J Obstet Gynaecol 2004; 21(1):58-60.

7. Sheth SS. Vaginal hysterectomy best practice and research. Clin Obstet Gynaecol 2005;19:307-332.

8. Gilpin SA, Goslingg JA, Smith AR, Warnell DW. The pathogenesis of genito urinary prolapse and stress in continence of urine: a histological and histochemical study. Br J Obstet Gynaecol 1989; 96(1):15:23.

9. Ezem BU, Otubu JA. Hysterectomy in the Hausa/ Fulani population in Nigeria. Int J Gynecol Obstet 1981; 19:145-149.

10. Sheth SS. Pre-operation sonograplnic estimation of uterine volume: an aid to determine the route of hysterectomy. J Gynecol Surg 2002; 18: 13-22.

11. Sheth SS. Vaginal or abdominal hysterectomy . In: Sheth SS, Studd J (Eds) Vaginal Hysterectomy. London: Martin Dumitz 2002; pp: 301-302.

12. Bhatta $\mathrm{N}(\mathrm{Ed})$. Hysterectomy and its aftermath. Jeffcoate's Principles Of Gynaecology $6^{\text {th }}$ International edition, London: Arnold, 2001; 785790.

13. Hawkins J, Hudson CN. Shaw's Textbook of Operative Gynecology, $5^{\text {th }}$ Ed, Edinburgh: Churchill Livingstone 1998; pp: 355-378. 